\title{
Las colecciones de documentos bajomedievales de las diócesis de Braga y Tui como fuente de estudio para la historia de la frontera gráfica*
}

\author{
The collections of late Middle Ages documents \\ of the dioceses of Braga and Tui as sources of \\ study for the history of the graphic border
}

\author{
Adrián ARES LEGASPI \\ Departamento de Historia Medieval y CC. y $\Pi$ T. Historiográficas \\ Universidad de Sevilla - Universidade do Porto, CITCEM \\ https://orcid.org/0000-0003-0241-4883 \\ aares@us.es
}

\begin{abstract}
The graphic culture of border territories became a complex historical reality due to the flow of people and the cultural and social influences which converged in these spaces. Consequently, this fact determined the type of documents which were issued, their formal elements or the types of scripts employed. In this research we shall present some of the collections of documents of the Arquivo Distrital de Braga and the Archivo Catedralicio de Tui which make it possible to study the graphic border between these two dioceses during the $14^{\text {th }}$ and $15^{\text {th }}$ centuries and the possibilities provided by the comparative analysis of some of their palaeographical and diplomatical features.
\end{abstract}

Keywords: Palaeography; ecclesiastical Diplomatic; written culture; medieval borders.
Resumen: La cultura gráfica en los territorios de frontera se convirtió en una realidad histórica muy compleja debido a los flujos de población e influencias culturales y sociales que convergieron en estos espacios; lo cual, además, determinó los tipos de documentos producidos, sus elementos formales o los modelos gráficos utilizados. En esta investigación presentamos algunos de los fondos documentales de los archivos Distrital de Braga y Catedralicio de Tui que nos permiten estudiar la frontera gráfica entre estas dos diócesis en los siglos XIV y XV y las posibilidades ofrecidas por el análisis comparativo de ciertos aspectos paleográficos y diplomáticos de sus componentes.

Palabras clave: paleografía; diplomática eclesiástica; cultura escrita; frontera medieval.

* Esta investigación ha sido posible gracias a la financiación del VI PPIT-US y al proyecto de investigación del Ministerio de Economía y Competitividad I+D: Iglesia y Escritura en el Occidente Peninsular (Castilla y Portugal). Siglos XII-XVII (HAR2017-85025-P). 


\section{INTRODUCCIÓN}

El estudio de la frontera es una cuestión que ha atraído la atención de los historiadores desde hace siglos y que «ha resurgido en los últimos años en el panorama historiográfico» ${ }^{1}$. Desde la noción de frontera como límite jurisdiccional entre entidades políticas distintas ${ }^{2}$, hasta la frontera como un elemento complejo en la que conviven (se entremezclan y oponen) todo un conjunto de factores sociales, económicos, culturales, mentales... ${ }^{3}$, esta temática ha sido abordada desde múltiples perspectivas (la historia medieval, la historia del arte, la filología...), en gran medida gracias a la naturaleza de la propia frontera medieval, puesto que esta era una realidad «abierta, vista y sentida en el imaginario colectivo, nunca mejor dicho; por definición se trata de una línea inventada, que es necesario imaginar» ${ }^{4}$. Una amalgama de concepciones a la que se viene a sumar durante las últimas décadas la idea del «otro» o la «otredad $»^{5}$; entendiendo la alteridad en materia religiosa ${ }^{6}$, de género ${ }^{7}$, etc.

1 Manuel GONZÁLEZ JiMÉNEZ, Fuentes para la historia de la frontera castellano-granadina, en Manuel Alejandro RODRÍGUEZ DE LA PEÑA (dir.), Hacedores de Frontera. Estudios sobre el contexto social de la Frontera en la España medieval, Madrid, 2009, p. 15.

2 Miguel Ángel LADERO QueSADA, Reconquista y definiciones de frontera, en Revista da Faculdade de Letras. História, 15 (1998), p. 656. Para una aproximación a la terminología y las acepciones de frontera, o centro y periferia: Daniel Power, Frontiers: Terms, Concepts, and the Historians of Medieval and Early Modern Europe, en Daniel POWER y Naomi STANDEN (eds.), Frontiers in question. Eurasian borderlands, 700-1700, Basingstoke, 1999, pp. 1-12; Edwar PETERS, Omnia permixta sunt: Where's the Border?, en The Medieval History fournal, 4, 1 (2001), pp. 109-127.

3 Son abundantes los trabajos monográficos y misceláneos que se pueden citar para ejemplificar la heterogeneidad de estas investigaciones. No obstante, por motivos de espacio, únicamente mencionamos aquí uno de los más recientes en el contexto de la Península Ibérica: Manuel García FERNÁNDEZ, Ángel Galán SÁNCHEZ y Rafael Gerardo PEINADO SANTAELla (eds.), Las fronteras en la Edad Media hispánica, siglos XIII-XVI, Granada, 2019. Para una revisión de la historiografía sobre la Corona de Castilla: Enrique Rodríguez PICAVEA, The Frontier and Royal Power in Medieval Spain: A Developmental Hypothesis, en The Medieval History fournal, 8, 2 (2005), pp. 273-301.

4 Carlos Barros Guimerans, La frontera medieval entre Galicia y Portugal, en Medievalismo, 4 (1994), p. 35. En esta misma dirección apuntaba Rodríguez Picavea: «a frontier is not only the historical reality that it represents, but also the conceptual image that historiography portrays». Enrique RODRÍGUEZ PICAVEA, The Frontier... [ver n. 3], p. 274.

5 Francisco García SERRANO, La creación de identidad en la frontera medieval hispana y la visión del otro: mudéjares y judios, en Manuel Alejandro RODRÍGUEZ DE LA PEÑa (dir.), Hacedores de Frontera. Estudios sobre el contexto social de la Frontera en la España medieval, Madrid, 2009, p. 78.

6 Emilio MiTre FERnÁNDEZ, El Occidente Medieval y el «otro», en XX Siglos, 5, 19 (1994), pp. 1422; Francisco García SerRano, La creación... [ver n. 5], pp. 73-90.

7 Carlee A. Bradbury y Michelle Moseley-Christian (eds.), Gender, Otherness, and Culture in Medieval and Early Modern Art, London, 2017. 
Ahora bien, lejos de ser los aspectos arriba señalados los únicos susceptibles de ser analizados en los contextos fronterizos, existen otros que todavía no han sido abordados desde este punto de vista, siendo el que aquí nos interesa el relativo a la cultura gráfica. La noción de frontera gráfica ha sido utilizada únicamente hasta el momento por Cabanes Catalá y Baldaquí Escandell para referirse a la situación vivida -en términos de historia de la escritura- en los territorios limítrofes entre las Coronas de Aragón y Castilla en el siglo XV, más concretamente a la influencia de los modelos gráficos empleados en el área murciana sobre las ciudades de Elche y Orihuela ${ }^{8}$. Una investigación que se centra en los componentes gráficos de las fuentes de ambos territorios, pero que deja a un lado, sin embargo, las cuestiones relacionadas con los elementos extragráficos, los cuales, además, en zonas fronterizas jugarían un papel de mucha mayor relevancia?.

El objetivo de este estudio, por lo tanto, es la presentación de una parte de los fondos documentales conservados actualmente en los archivos Distrital de Braga y Catedralicio de Tui, así como la descripción detallada de algunas de las características -paleográficas y diplomáticas- que nos permiten afrontar la historia de la escritura en ambas diócesis en la Baja Edad Media. Una historia tanto de las formas gráficas (la morfología de las letras, del sistema de abreviación, de los modos de ejecución y la evolución de todos ellos) como de los factores extragráficos (tipologías documentales, soportes materiales, notarios y escribanos, lengua...) que ha de ser leída en clave comparativa (incluso en parangón con otras sedes limítrofes como la compostelana) y en la cual, las similitudes y diferencias que caracterizan la cultura gráfica de ambas «provincias escriturarias» ${ }^{10}-\mathrm{O} \ll$ territorios diplomáticos» ${ }^{11}$ - nunca son estáticas, sino que se transforman en el plano diacrónico y sincrónico debido

8 María Luisa CABANES CaTAlá y Ramón BALDAQuí EsCANDEll, La regionalización de la escritura en zonas de frontera gráfica. El caso de la gobernación de Alicante, en Otto KRESTEN y Franz LACKNER (eds.), Régionalisme et internationalisme: problèmes de paléographie et de codicologie du Moyen Âge, Wien, 2008, pp. 177-188.

9 Si tenemos en cuenta que los factores extragráficos de una escritura son «les faits historiques, sociaux et culturels qui sous-tendent la production écrite», la historia externa que «place les documents graphiques dans leur contexte communicatif» (Irene CECCHERINI, Structure et style: observations paléographiques pour l'étude des écritures cursives à Florence aux XIII et XIVe siècles, en Sébastien BARRET, Dominique STUTZMANN y Georg VOGELER (eds.), Ruling the script in the Middle Ages, Turnhout, 2016, p. 122), es lógico esperar que en contextos donde existe una mayor pluralidad de hechos históricos, sociales y culturales, como en los espacios fronterizos, también la difusión y socialización de los modelos gráficos sea mayor.

10 María Luisa Cabanes CaTAlá y Ramón BALDAQuí ESCANDELl, La regionalización... [ver n. 8], p. 178.

11 El concepto de «territorios diplomáticos» o «Urkundenterritorien» y otros como «Urkundenlandschaft» fueron acuñados por Heinrich von FICHTENAU, Das Urkundenwesen in Österreich vom 8. bis zum frïben 13. Jabrbundert, Wien, 1971, p. 256. 
a lo «permeable (de) la frontera medieval galaico-miñota» ${ }^{12}$ y a la existencia en esta zona de tres espacios de escrituración distintos: el del arzobispado de Braga, el del obispado de Tui y el del obispado de Tui en el área conocida como Entre Miño y Limia, o Entre Minho e Lima, en portugués.

El Entre Minho e Lima es el territorio ubicado entre estos dos ríos y que dan nombre a esta demarcación, en la parte más septentrional de Portugal, el cual, con la independencia del reino portugués, pasa a estar subordinado al nuevo poder en el ámbito legislativo-gubernamental, mientras que en el religioso seguía perteneciendo a la diócesis de Tui ${ }^{13}$. Consecuentemente, esta situación derivó en constantes tensiones y conflictos entre la Corona portuguesa y el obispado tudense ${ }^{14}$, en gran medida «debido a las tierras que este tenía en el vecino reino» ${ }^{15}$; aunque al mismo tiempo, como subraya José Marques, «contribuiria para flexibilizar a fronteira do Minho» ${ }^{16}$.

12 Carlos Barros Gutmerans, La frontera... [ver n. 4], p. 28.

13 Avelino Jesús da Costa, A comarca eclesiástica de Valença do Minho (Antecedentes da diocese de Viana do Castelo), en I Coloquio galaico-minhoto, Ponte de Lima, 1981, pp. 69-240; Teresa de Jesus RODRIGUES, O Entre Minho e Lima de 1381 a 1514: antecedentes e evolução da comarca eclesiástica de Valença do Minho, Viana do Castelo, 2002. Según afirma Barros Guimeráns: «sabemos que la frontera política recién creada no afectaba a las fronteras eclesiásticas, las cuales durante más de doscientos años no tienen para nada en cuenta la línea de demarcación entre dos estados». Carlos BARRos GUIMERANS, La frontera... [ver n. 4], p. 30.

14 José Marques, A fronteira do Minho, espaço de convivência galaicho-minhota, na Idade Média, en Estudos em Homenagem a Luís António de Oliveira Ramos, Porto, 2004, p. 704. En otras ocasiones la conflictividad se produjo entre las Coronas de Castilla y Portugal con objeto del dominio de la ciudad prelaticia de Tui: Pascual Galindo RomeO, Tuy en la Baja Edad Media: siglos XII-XV, Zaragoza, Madrid, 1923; Inés CALDERÓN MEDINA, Reyes, nobles y frontera. Entre la violencia y el parentesco en el espacio fronterizo galaico portugués (siglo XII-XIII), en Cuadernos de Estudios Gallegos, 64 (2017), pp. 91-117. Para aspectos relacionados con el papel de las monarquías y la nobleza en estos territorios de frontera: Luís Adão da FONSECA (coord.), Entre Portugal e a Galiza (Sécs. XI a XVII). Um olhar peninsular sobre uma região histórica, Porto, 2014; João Paulo Martins FERREIRA, A Nobreza Galego-Portuguesa da Diocese de Tui (915-1381), Santiago de Compostela, 2019.

15 Paz Romero PorTilla, Relaciones entre Portugal y Galicia. Siglo XIV-XV, en Revista da Faculdade de Letras. História, 9 (2008), p. 218. Tui fue diócesis sufragánea de Braga hasta finales del Trescientos, cuando pasó a serlo de Santiago. Demetrio MANSILla ReOYO, Geografía eclesiástica de España: estudio histórico-geográfico de las diócesis, Roma, 1994, vol. 2, pp. 126-129.

16 José MARQUeS, Relações fronteiriças luso-castelhanas, nos séculos XIV-XV, en ID., Alto-Minho e Galiza. Estudos históricos, Monção, Braga, Melgaço, 2017, p. 455. Una flexibilidad que, como apuntan otros investigadores, se transmitiría también a las sociedades de frontera: «la diversidad tanto dentro de los reinos cristianos como de los islámicos y la fluidez que se daba en la frontera, proporcionaron un carácter flexible a las sociedades peninsulares». Francisco GarcÍA SERRANO, $L a$ creación... [ver n. 5], p. 76. Para una visión integral del mundo tudense en esta época: Ermelindo PORTELA SILVA, La región del obispado de Tuy en los siglos XII a XV: una sociedad en la expansión y en la crisis, en Compostellanum, 20, 1-4 (1975), pp. 1-468. 
La flexibilidad de los límites existentes en esta zona entre Castilla y Portugal se hizo patente en múltiples aspectos de la vida cotidiana, siendo el que aquí más nos interesa el relativo a la administración eclesiástica ${ }^{17}$. Una de las singularidades de la diócesis de Tui era la posesión de beneficios eclesiásticos en ambos reinos ${ }^{18}$, lo cual provocó un gran trasiego de clérigos y comitivas prelaticias que cruzaban el Miño en ambos sentidos (en viajes de ida y vuelta) para tratar asuntos pastorales o jurídico-canónicos tanto en los «serviços centrais diocesanos de Tui» como en las feligresías al sur del paso fluvial ${ }^{19}$. Del mismo modo, la presencia de gallegos en territorio portugués se constata entre los candidatos a recibir las órdenes sagradas en el arzobispado bracarense, puesto que, tal y como ha demostrado José Marques, en las matrículas de ordens del período 1430-1468 figuran quinientos noventa y siete solicitantes procedentes de las diócesis gallegas (de los cuales doscientos cuarenta y dos provienen de Tui y doscientos veintiocho de Ourense), mientras que para la misma cronología solo sesenta y cinco lo hacen de otras sedes castellanas, navarras y aragonesas ${ }^{20}$. Un vínculo que se extendió, además, a la esfera económica de la administración capitular, ya que la corporación tudense cobraba rentas de diversas iglesias situadas en el Entre Minho e Lima, así como ostentaba la titularidad de múltiples propiedades ${ }^{21}$.

Ahora bien, esta situación se volvió mucho más compleja a partir de 1381, cuando varios canónigos de Tui abandonaron la sede capitular y se instalaron al

17 Otro de los ámbitos en los que ha profundizado con detenimiento la historiografía es el de las influencias artísticas en este espacio fronterizo: Ramón YZQUIERDO PERRÍN, Talleres de Tui, Bragay Zamora en la arquitectura románica del norte de Portugal y Galicia, en Anuario Brigantino, 39 (2016), pp. 195-218; Margarita VÁZQUEZ CORBAL, Entre Galicia y Portugal: la catedral de Tui y el rol de la frontera en la génesis y evolución del arte medieval en los siglos XIII y XIV, en Manuel GARCÍA FERNÁNDEZ, Ángel GaLÁN SÁNCHEZ y Rafael Gerardo PEINAdo SANTAELla (eds.), Las fronteras en la Edad Media hispánica, siglos XIII-XVI, Granada, 2019, pp. 673-683.

18 Paz Romero Portilla, Un Observatorio privilegiado de las relaciones entre Castilla y Portugal: Tuy en la Edad Media, en Estudos em homenagem ao professor doutor Fosé Marques, vol. 4, Porto, 2006, p. 248.

19 José MARQUES, Relações fronteiriças... [ver n. 16], p. 456. Un ir y venir de gentes que, según el propio Marques, era «a melhor prova de que a fronteira política era mais psicológica do que real». José MARQUES, O Entre Minho e Lima: da diocese de Tui à diocese de Ceuta, en Manuel GONZÁLEZ JimÉNEZ y Isabel MonTes Romero-CAMACHO (eds.), La Península Ibérica entre el Mediterráneo y el Atlántico. Siglos XIII-XV, Sevilla, Cádiz, 2006, p. 486.

20 José MARQUeS, Relações galaico-bracarenses, no século xv, segundo as matrículas de ordens do Arquivo Distrital de Braga, en I Coloquio galaico-minhoto, Ponte de Lima, 1981, pp. 339-359, y especialmente Quadro $n^{\circ} 1$ y 2.

21 José MARQues, O Censual do Cabido de Tui para o arcediagado da Terra da Vinha 1321, en ID., AltoMinho e Galiza. Estudos históricos, Monção, Braga, Melgaço, 2017, pp. 367-393. 
otro lado de la frontera, en la ciudad de Valença do $\mathrm{Minho}^{22}$, con motivo de la adhesión de la monarquía portuguesa al pontífice romano, mientras que Castilla se mantenía fiel al aviñonense ${ }^{23}$. Desde entonces, la nueva corporación, emplazada en la colegiata de Valença (creada a principios del Cuatrocientos por Juan García de Manrique en la iglesia de Santo Estevo y a la que se le habían anexionado los arcedianazgos de Cerveira y Labruja ${ }^{24}$, administraría distintas prebendas, beneficios y hasta doscientas treinta feligresías ${ }^{25}$, para lo cual la escritura se convertiría en un recurso imprescindible. Esto dio lugar, por lo tanto, a la conformación en el tránsito del siglo XIV al XV de tres espacios de escrituración bien definidos en cuanto a la jerarquía y funciones de sus oficinas (Braga, Valença y Tui) ${ }^{26}$, pero con un contacto muy intenso entre sí, por lo que en ocasiones es muy difícil detectar las particularidades de cada sede dentro del continuиm que en ciertos aspectos de la cultura gráfica de esa época supuso el territorio que iba desde Braga a Tui.

\section{LOS FONDOS DOCUMENTALES}

Las fuentes que hemos seleccionado para el estudio comparado de la cultura gráfica de estas diócesis fronterizas son los diplomas conservados en el Arquivo Distrital de Braga y en el Archivo de la Catedral de Tui, en la denominada Colección Cronológica del primero y en las carpetas de pergaminos sueltos del segundo ${ }^{27}$. Se trata de dos fondos compuestos por piezas tanto de la Edad Media como de la Moderna, siendo, en el caso de la primera, documentos emitidos abrumado-

22 Ernesto Iglesias AlmeIda, O antigo bispado de Tui en Portugal, Noia, 2008, p. 103.

23 José MARQues, O Entre... [ver n. 19], p. 484. No se debe olvidar tampoco, como señala el propio Marques en estas páginas, que «esta rebelião teve o apoio do rei de Portugal».

24 Ernesto Iglesias AlmeIDA, $O$ antigo... [ver n. 22], p. 105. No abordamos aquí la historia de este territorio durante el siglo XV por motivos de espacio. Si bien, este se caracterizó por los cambios en su pertenencia jurisdiccional: a la vez que se produjo un período de vacancia o que se eligieron varios titulares, en 1452 se consumaba definitivamente la anexión de Valença a la diócesis de Ceuta, hasta que, finalmente, en 1514 la zona de Entre Minho e Lima pasó a formar parte del arzobispado de Braga. Para esta evolución: José MARQUES, O Entre... [ver n. 19], pp. 481-498; y con más detalle: Teresa de Jesus RodRIGUES, O Entre... [ver n. 13].

25 Francisco Ávila y La CUEVA, Historia civil y eclesiástica de la ciudad de Tuy y su obispado, edición facsímil, Santiago de Compostela, 1995, t. 3, p. 309.

26 La situación precedente a esta separación se caracterizó, por lo tanto, por la existencia únicamente de dos cancillerías, la arzobispal de Braga y la episcopal de Tui.

27 Braga, Arquivo Distrital de Braga, Colección Cronológica (Braga, ADb, CC a partir de ahora) y TUI, ARChIvo CATEDralicio DE TUI, Carpetas de documentos sueltos (TUI, ACT, C., doc. en adelante). 
ramente en pergamino. No obstante, en términos numéricos la balanza se desequilibra en favor de la institución bracarense debido al gran volumen que conserva: algo más de mil quinientos diplomas otorgados hasta 1500; mientras que la catedral de Tui solamente alberga cuatrocientos veinticuatro. Si bien, a pesar de la diferencia cuantitativa, la gran variedad tipológica de las piezas de ambos archivos hace posible establecer -de una manera fiable desde el punto de vista de la metodología- una investigación como la aquí propuesta.

Por una parte, las carpetas 1-5 (ciento cinco diplomas) del Archivo de la Catedral de Tui contienen documentos reales, expedidos tanto por los reyes castellanoleoneses como por los portugueses; las 6-8 (cuarenta y siete) poseen diplomas procedentes de las oficinas papales, ya sean las radicadas en Roma o las ubicadas en Aviñón; y las restantes, 9-15 (doscientos setenta y dos), incluyen pergaminos procedentes sobre todo del ámbito del derecho privado (actuando como otorgantes normalmente individuos particulares ${ }^{28}$ ) y de autoridades religiosas como el cabildo y el obispo de Tui, aunque también de otras entidades más pequeñas como los monasterios de Santa María de Oia o los ya desaparecidos de San Salvador de Barrantes, San Salvador de Budiño y Santa María de Tomiño ${ }^{29}$. Por otra parte, aunque en la Colección Cronológica de Braga no se dividen las piezas según su procedencia, podemos establecer igualmente un cuadro institucional similar al contar con una gran cantidad de documentos reales y pontificios, otros emanados del cabildo y arzobispo bracarenses, de los notarios públicos de la ciudad y otros territorios ejerciendo en el mundo del derecho privado y, finalmente, de monasterios como el de Santa Maria de Pombeiro.

Ahora bien, dentro de este escenario de corporaciones emisoras de documentación, y a efectos del estudio de la cultura gráfica de frontera, sobresalen en esta serie del Arquivo Distrital de Braga los pergaminos otorgados a partir de 1385 por los vicarios y administradores del obispo de Tui en el Entre Minho e Lima. Más que por la especificidad de sus elementos materiales, apenas existente en lo sustancial, estos diplomas destacaron por los factores extragráficos que rodearon su escrituración y su uso; es decir, por los condicionantes esencialmente

28 No solo vecinos de los territorios pertenecientes al prelado tudense, sino también -y muy frecuentemente- de zonas de jurisdicción real (Baiona) o de señoríos laicos (la tierra de Sobroso en propiedad de las familias García y Soutomaior).

29 Hasta aquí nos hemos referido a las instituciones gallegas próximas a la frontera política con Portugal. Si bien, cabe señalar que entre los pergaminos de las carpetas 9-15 de Tui también encontramos diplomas procedentes de los arzobispos compostelanos o de figuras judiciales concretas como algún pertiguero de Santiago, varios gobernadores y merinos reales en Galicia o diversos jueces apostólicos. 
sociales e institucionales del momento y lugar en que se crearon. Es por esto que, aunque descenderemos con mayor profundidad en los componentes diplomáticos más adelante, debemos apuntar aquí algunas de las características de la arquitectura documental que tenían en común las oficinas de los dos obispos y el arzobispo; es decir, el «esquema de diversas tipologías documentales que se elaboran con el objetivo de cumplir diferentes funciones y las interrelaciones existentes entre tales tipologías» ${ }^{30}$.

En la Colección Cronológica del Arquivo Distrital de Braga se conservan para la Baja Edad Media decenas de confirmaciones de iglesias realizadas por los arzobispos bracarenses en las cuales se concedía la titularidad de las mismas a miembros del sector eclesiástico. Igualmente, fue muy frecuente que los «bispos de Tui na parte de Portugal» ${ }^{31}$-o sea, los asentados en Valença después de 1381- otorgasen este mismo tipo de diplomas (cincuenta y nueve) para las iglesias bajo su jurisdicción ${ }^{32}$. Unas confirmaciones que, de nuevo, se produjeron para las posesiones de la sede tudense en suelo gallego (en este caso en las carpetas de documentos sueltos del Archivo de la Catedral de Tui solamente se conservan siete diplomas ${ }^{33}$ ), pero que la historiografía española sobre diplomática eclesiástica ha denominado colaciones de beneficios ${ }^{34}$. $\mathrm{Al}$ mismo tiempo, también podemos observar que, en las tres instituciones, podían ser tanto los obispos o arzobispo como algún delegado o representante suyo los que intitulasen estas concesiones: los vicarios en lo espiritual y temporal de cada autoridad, los cuales, además, fueron la cabeza de

30 Néstor VigIL MonTES, De la unidad a la diversificación, los nuevos usos escriturarios en la gestión del patrimonio capitular de Oviedo, en Francisco J. MOLINA DE LA TORRE, Irene RUIZ AlbI y Marta HeRrero DE LA FUENTE (eds.), Lugares de escritura: la catedral, Valladolid, 2014, p. 469.

31 Así se intitularon los titulares en Valença Turibio (1382-1398) o Antonio de Lisboa (1406-1414): BRAGA, ADB, CC, 893, 899, 918, 919 y 930 para el primero 977, 987 y 992 para el segundo. Sin embargo, tanto João Afonso (1422-1465) como su sobrino y sucesor, João Afonso Ferraz (14651477), se intitulan «administrador perpetuo do bispado de Tui na parte de Portugal»: BRAGA, ADB, CC, $1036,1045,1084 \ldots$ para el primero y $1347,1349,1354 \ldots$ para el segundo. Cabe destacar que la fecha de actuación de João Afonso Ferraz es a día de hoy incierta. Mientras que José Marques la sitúa entre 1472 y 1477 (José MARQUES, O Entre... [ver n. 19], p. 492), Iglesias Almeida lo hace entre 1465 y 1477 (Ernesto IGLESIAS AlmEIDA, O antigo... [ver n. 22], p. 109). Eso sí, ambos autores establecen con reservas el final del gobierno del primer João Afonso, el tío del segundo, en 1465. Finalmente, con la anexión de Valença a la diócesis de Ceuta, João Afonso Ferraz suma a su intitulación «lecto do bispado de Cepta»: BRAGA, ADB, CC, 1354, 1355, 1357 y 1361.

32 Una muestra de estos documentos en $n .31$ de este trabajo.

33 TUI, АCT, C. 11 , doc. 5; C. 12, doc. 26; C. 14, docs. 28, 29, 45, 58 y 82.

34 María Milagros CÁRCEL ORTÍ, El documento episcopal: estado actual de sus estudios, en Boletín de la Sociedad Castellonense de Cultura, 58, 3 (1982), pp. 471-511; Francisco Reyes MARsILla DE PASCUAL, En torno a la diplomática episcopal y capitular castellana bajomedieval: una aproximación, en Miscelánea medieval murciana, 19-20 (1995-1996), pp. 153-172. 
la jerarquía en tiempos de sede vacante. Una realidad especialmente definitoria de la «irregularidade canónica ${ }^{35}$ que caracterizó la gobernanza de la parte de Portugal perteneciente a la diócesis de Tui ${ }^{36}$.

Otras tipologías documentales que nos permiten continuar esta comparación entre los diplomas emanados de las administraciones eclesiásticas eran las uniones entre beneficios o bien la anexión de estos a las mesas capitulares de cada sede ${ }^{37}$; las concordias establecidas entre las autoridades de estas diócesis ${ }^{38}$ o las sentencias emitidas por los distintos jueces eclesiásticos (normalmente figuras vinculadas a otras dignidades: arcedianos, tesoreros catedralicios, deanes, abades... ${ }^{39}$ ), siendo algunos de ellos comisionados por el pontífice ${ }^{40}$.

Los diplomas otorgados por los prelados y el resto de autoridades eclesiásticas no solo fueron el resultado del ejercicio de sus funciones, sino que también surgieron como consecuencia del desarrollo de múltiples negocios en el mundo privado, principalmente en la esfera de su hacienda ${ }^{41}$. De este modo, como veremos en el siguiente epígrafe al tratar los cambios en las fórmulas diplomáticas, los obispos y cabildos catedralicios otorgaron una infinidad de foros, compraventas, arrendamientos, o bien fueron destinatarios de estas transacciones, así como de donaciones, dotaciones de capellanías, etc., las cuales implicaban la existencia de unos mecanismos diplomáticos y gráficos distintos a los consignados en la documentación anterior, pero que igualmente muestran las características del continиит en materia de cultura escrita que venimos analizando.

Ahora bien, los obispos y cabildos no fueron las únicas instituciones del sector eclesiástico que, a través de su documentación, posibilitan el estudio de la frontera gráfica luso-castellana. Los monasterios fueron los otros centros de escritura que impulsaron la transferencia de otorgantes y de profesionales de la pluma de un territorio a otro ${ }^{42}$. Organismos, unos en suelo portugués, como por

35 José Marques, O Entre...[ver n. 19], p. 492.

36 Ernesto Iglesias AlmEIDA, $O$ antigo... [ver n. 22], p. 106.

37 Para la casuística bracarense: BRAGA, ADB, CC, 1095, 1186, 1247 ...; para la de las iglesias de Entre Minho e Lima: BRAGA, ADB, CC, 1203, 1210, 1253; y para Tui: TUI, ACT, C. 11, doc. 13 y C. 13, doc. 15.

38 TUI, ACT, C. 9, doc. 20.

39 Para Braga: BRAGA, ADB, CC, 968, 1382, 1495; para Valença: BRAGA, ADB, CC, 1200; y para Tui: TU, ACT, C. 10, doc. 20; C. 11, docs. 6, 7; C. 12, docs. 6, 15; C. 13, docs. 23, 35.

40 En Braga: Braga, ADB, CC, 1010; y en Tui: ACT, C. 9, doc. 18.

41 José MARQUES, Relações económicas do norte de Portugal com o Reino de Castela, no século XV, en ID., Alto-Minho e Galiza. Estudos históricos, Monção, Braga, Melgaço, 2017, pp. 493-530.

42 Sin embargo, ante las quejas de los clérigos portugueses de la diócesis tudense sobre la obligatoriedad impuesta por el prelado de que sus documentos debían pasar ante notarios de Tui, en 1307 
ejemplo el monasterio de Santa Maria de Fiães, con posesiones al otro lado del río Miño ${ }^{43}$, y otros asentados en zonas gallegas, como el de Santa María de Tomi$\tilde{n} \mathrm{o}^{44}$ o el de Santa María de Oia cuyas propiedades no solo llegaban al Entre Minho e Lima, sino que -en el caso de este último- se ubicaban en los alrededores de Lisboa $^{45}$ y que, además, mantuvo una relación constante con la monarquía lusa ${ }^{46}$.

Hasta aquí hemos visto cuáles fueron las principales instituciones eclesiásticas de ambas diócesis que, gracias al uso habitual de documentación -conservada hoy en los archivos de Braga y Tui-, revelan la naturaleza de los diferentes aspectos de la frontera medieval en este espacio. Unas fuentes que en ocasiones ya han sido editadas, como el Censual de Tui ${ }^{47}$ o el Libro de confirmações de Tui ${ }^{48}$; que en otras se recogen como compendios regidos por una temática concreta ${ }^{49}$; o bien, que han sido de interés de los investigadores como piezas sueltas ${ }^{50}$. No obstante, a continuación veremos cómo se pueden aprovechar los dos fondos que suponen el objeto de estudio de este trabajo para la historia comparada de la cultura gráfica de varias provincias escriturarias, o en otras palabras, los componentes de los diplomas que nos permiten abordar el análisis de la frontera gráfica.

el rey Dinís «ordenaba que non se puidesen outorgar instrumentos ante aqueles notarios, e os que así fosen escritos serían nulos». Suso VILA Botanes, A cidade de Tui durante a Baixa Idade Media, Noia, 2009, pp. 59-60.

43 José MARQues, O Cartulário do Mosteiro de Fiães (ADB, MS. 1052), Melgaço, 2016.

44 Como ejemplos de esta realidad, en el Archivo Catedralicio de Tui se conserva un documento realizado en 1449 en Ponte de Lima por el notario Affonse Anes, tabaliom real de noso senhor el rey, en el cual se consignan las propiedades que tenía el cenobio de Santa María de Tomiño en esa zona de Portugal. TUI, ACT, C. 12, doc. 14.

45 José Marques, O Mosteiro de Oia e a Granja da Silva, no contexto das relações luso-castelhanas dos séculos XIV-XV, en Revista de histórica, 6 (1985), p. 98.

46 Ermelindo PORTELA SILVA, Tiempos de reforma y espacios de frontera. En torno a los orígenes del monasterio de Santa María de Oia, en Revista Chilena de Estudios Medievales, 12 (2017), pp. 49-60; Ana Paula Leite RODRIGUES, Nos dois lados do rio Minho: o senhorio transfronteiriço do mosteiro de Santa Maria de Oia (séculos XII a XV), Vigo, 2017; Ana Paula Leite RODRIGUES, En torno a un territorio periférico y fronterizo: la relación del Monasterio de Santa María de Oia con el poder regio portugués (siglos XII a XV), en Studia Historica. Historia Medieval, 34 (2016), pp. 215-242.

47 José MARQues, O Censual... [ver n. 21], pp. 367-393.

48 José MARques, Confirmações de Tui (1352-1382): aspectos do episcopado de D. Foão de Castro, Braga, 2018. No se trata de diplomas sueltos, sino de un libro registro de cuyo contenido, sin embargo, no hemos encontrado en los archivos de Braga y Tui ningún ejemplar suelto expedido en pública forma.

49 Paz Romero Portilla, Valor de la documentación real portuguesa para la bistoria de Galicia en la Edad Media, en Cuadernos de Estudios Gallegos, 51 (2004), pp. 219-237.

50 Miguel Calleja PuerTa, Notarios públicos entre dos reinos. Apuntes diplomáticos sobre documentos notariales castellanos en el Arquivo Distrital de Braga, en Espacio, Tiempo y Forma. Serie III, Historia Medieval, 33 (2020), pp. 69-96. 


\section{LOS FONDOS DOCUMENTALES Y EL ESTUDIO SOBRE FRONTERA GRÁFICA}

Serán dos tipos de componentes de la documentación los que nos sirvan como hilo conductor en este epígrafe, los paleográficos y los diplomáticos; aunque con referencias a algunos de otro carácter, filológico, por ejemplo, que complementan la información aportada por los primeros.

En cuanto a la escritura empleada al norte y al sur del río Miño, el examen paleográfico de las dos colecciones documentales arroja luz sobre los diferentes modelos gráficos en uso en cada territorio y su evolución diacrónica, así como las influencias que se pueden producir entre todos ellos. De hecho, según afirman Cabanes Catalá y Baldaquí Escandell, «son las semejanzas formales, más que cualquier otro elemento, las que importan para determinar unos paralelismos que son el testimonio de relaciones culturales y de influencias mutuas entre tierras $\gg^{51}$. Un análisis comparativo para el cual debemos establecer, primero, una jerarquía a la hora de aproximarnos a los tipos de escritura, pues estos varían dependiendo del uso y función de cada una; es decir, de las oficinas y las tipologías diplomáticas en las que se utilizan ${ }^{52}$. Tras ello, el siguiente paso es aproximarse a esa jerarquía desde una doble perspectiva, vertical y horizontal. La primera es la correspondiente a la organización gráfico-documental en cada institución, mientras que la segunda se refiere a la confrontación entre los niveles del esquema dibujado para cada uno de los organismos.

Los fondos bracarenses y tudenses nos permiten proceder, en este sentido, de forma extensa, pues, como vimos en el apartado precedente, en ellos hay una gran pluralidad de tipos documentales y, sobre todo, equiparables entre diócesis $^{53}$. El examen de las concesiones de beneficios eclesiásticos, los documentos ubicados en la cúspide, y por lo tanto más solemnes desde el punto de vista de

51 María Luisa Cabanes Catalá y Ramón BALDAQuí EsCANDELl, La regionalización... [ver n. 8], p. 178.

52 Esta visión del uso y variación de los modelos gráficos en función del tipo de scriptorium y producto escrito ya la ensayamos en: Adrián AREs Legaspi, La escritura en Santiago de Compostela en el tránsito de la Edad Media a la Edad Moderna, Tesis doctoral inédita, Universidad de Sevilla, 2019.

53 Las oficinas eclesiásticas de Braga son las que mejor se conocen desde el punto de vista institucional y de la diplomática. Para la Plena Edad Media: Maria Cristina ALmEIDA E CunHA, A chancelaria arquiepiscopal de Braga (1071-1244), Noia, 2004. Para la Baja Edad Media: José MARQUES, O regimento da Chancelaria Arquiepiscopal de Braga no século XV: tipologia documental e taxas, en Revista da Faculdade de Letras. História, 9 (1992), pp. 87-106; José MARQUES, A chancelaria e a diplomática arquiepiscopais de Braga nos finais da Idade Média, en Revista de História, 12 (1993), pp. 25-46. Para el cabildo de Tui, aunque más superficialmente: María del Carmen SÁNCHEZ CARRERA, El Bajo Miño en el siglo XV: el espacio y los hombres, A Coruña, 1997, pp. 228-231. 
su contenido y de sus componentes materiales, evidencia una clara similitud en términos gráficos, al emplearse en ellos desde la década de 1330 una mixta francesa, tipificada ya en los años $40^{54}$. Esta comparativa se enriquece todavía más si la prolongamos a la cultura gráfica de las diócesis colindantes con estas dos en la fachada atlántica, ya que, en vista de los diplomas de las sedes de Oporto y Santiago de Compostela, la cronología de la introducción de esta escritura de origen ultrapirenaico se asemeja más a lo ocurrido en la primera que en la segunda ${ }^{55}$. Un modelo gráfico que aparece también en algunas de las confirmaciones más antiguas otorgadas en los últimos años del Trescientos en Valença por parte de los vicarios de los administradores del obispado de Tui en Portugal ${ }^{56}$.

No obstante, la distribución gráfica sufrió transformaciones tanto en el plano diacrónico como sincrónico. En cuanto al primero, no hace falta abandonar este grado de la jerarquía para percibir una divergencia entre la realidad bracarense, la del Entre Minho e Lima y la tudense. A pesar de que la mixta de las confirmaciones de las tres diócesis sufre un proceso en el que sus trazos ganan redondez con el paso de los decenios o una evolución en la morfología de ciertas letras, en los títulos de beneficios expedidos en Tui se observa cómo en los años 80 del siglo XV se van introduciendo elementos de la humanística ${ }^{57}$; mientras que en los otros dos territorios se mantienen los rasgos cursivos más propios del ciclo gótico, debido en gran medida, como luego veremos, a la utilización del portugués en estos diplomas ${ }^{58}$.

54 Marc SMITH, L'écriture de la chancellerie de France au XIV siècle: observations sur ses origines et sa diffusion en Europe, en Otto KRESTEN y Franz LACKNER (eds.), Régionalisme et internationalisme: problèmes de paléographie et de codicologie du Moyen Âge, Wien, 2008, pp. 279-298.

55 Para el caso compostelano: Adrián AREs LEGASPI, La escritura ... [ver n. 52], pp. 285 y ss; mientras que para el portuense: Maria João OlIVEIRA E SILVA, A escrita na catedral. A chancelaria episcopal do Porto na Idade Média, Porto, 2013, pp. 249-251. Los motivos de estas diferencias en el plano cronológico no son objeto de esta investigación debido al espacio que requeriría el tema. No obstante, habría que preguntarse si la presencia -por corta que fuese- de individuos franceses en las iglesias bracarense y tudense, como la del obispo de Tui en 1324, Bernardo Guido, pudo tener consecuencias sobre la cultura gráfica de las diócesis, al menos en las oficinas eclesiásticas. Suso Vila Botanes, $A$ cidade... [ver n. 42], p. 61.

56 BRAGA, ADB, CC, 918 o 933.

57 ТUा, АСТ, C. 12, doc. 29; C. 13, doc. 15.

58 BRAGA, ADB, CC, 1361, 1473 o 1490. Según los estudios de José Marques, los primeros síntomas del cambio gráfico hacia la humanística aparecen, de hecho, no en los originales expedidos en pública forma de estos diplomas, sino, «na sua grande maioria, de registos de algumas cartas de confirmação de benefícios paroquiais e de deliberações tomadas pelo prelado na sequência de visitas pastorais». José MARQUES, Prácticas paleográficas em Portugal no século XV, en Revista da Faculdade de Letras do Porto, Ciências y Técnicas do património, Série I, 1 (2002), p. 80. 
Por otra parte, en lo relativo a las variaciones sincrónicas, es al descender en los escalafones de la tipología documental donde se aprecian las diferencias más marcadas en la frontera gráfica. Esto se explica por la sustitución del latín por el romance -sea portugués, gallego o castellano-y, a su vez, de la mixta francesa por las cursivas autóctonas en diplomas como aforamientos o compraventas. En otras palabras, en los negocios del derecho privado, aunque estos sean otorgados por los prelados. En las sedes de Braga y Valença comprobamos que algunas de las características más genuinas de la mixta se mantienen en esos documentos (inclinación de las letras hacia la derecha, preferencia por las ligaduras de abajo arriba, supervivencia de los remates afilados de los caídos de $f$ y $s$ a la vez que se ensanchan en su tramo medio) ${ }^{59}$, aunque adquiriendo el trazado en la composición un aspecto, en general, mucho más redondeado e incluso, ya a mediados del Trescientos, apareciendo algún elemento compartido con la tradición castellana como los envolventes dextrógiros en los caídos de ciertas letras ${ }^{60}$. $\mathrm{Al}$ mismo tiempo que ocurría esto al sur del Miño, en los diplomas de este tipo expedidos en la parte septentrional del obispado de Tui se observa un proceso similar pero con una filtración de los componentes de la mixta mucho menor; es decir, en la cadena gráfica de los documentos en gallego los trazos curvos ganan mucho más terreno a los angulosos de la mixta, los bucles se vuelven más redondeados y la proporción entre las ligaduras de abajo arriba y las de la cabeza de una letra al pie de la siguiente se equilibra, cuando no se inclina claramente en favor de estas últimas ${ }^{61}$.

En definitiva, en lo que a las cuestiones paleográficas se refiere, el parangón entre los fondos de Braga y Tui muestra cómo a medida que avanza el siglo XV la cultura gráfica tudense se aleja de la bracarense y se aproxima a la que se desarrolla en sus márgenes septentrionales, en la diócesis compostelana, y, por extensión, en la Corona de Castilla ${ }^{62}$. Se podría decir, pues, que la frontera gráfica en el río Miño -coincidiendo con la divisoria política- crece, se ensancha, mientras que la

59 Unas características gráficas que son unos de los principales componentes de la conocida como «letra joanina» y cuya codificación en este nuevo modelo podría explicar la larga pervivencia de estos elementos. Para la citada letra, cuya denominación procede del período en que se origina, el reinado de Juan I: Eduardo NunEs, Album de Paleografia Portuguesa, Lisboa, 1969, p. 12.

60 José MARQues, Prácticas... [ver n. 58], pp. 73-96.

61 Del mismo modo que en el siglo XIV algún obispo de Tui era de origen francés, en el XV se aúpan a lo más alto de la sede tanto familias nobiliarias autóctonas como procedentes de otras áreas castellanas. José GARCÍA ORO, Galicia en los siglos XIV y XV, A Coruña, 1987, t. 1, pp. 182 y ss. y t. 2, pp. 130 y ss.

62 María Josefa SAnZ Fuentes, La escritura gótica documental en la Corona de Castilla, en María Josefa SANZ Fuentes y Miguel CALleja PuERTA (coords.), Paleografía II: las escrituras góticas desde 1250 hasta la imprenta, Oviedo, 2010, pp. 107-126. 
que separa a Tui del resto de las diócesis gallegas, y de la tradición gráfica castellana en general, disminuye, se estrecha.

La segunda dimensión de la frontera gráfica que nos permite abordar la comparación de las colecciones documentales de Braga y Tui es la concerniente a la diplomática de los productos escritos emitidos en estas provincias escriturarias. Los aspectos que se podrían tratar en este sentido son múltiples (la génesis documental, los caracteres internos y externos de los diplomas, su tradición, el notariado desde todas sus perspectivas...). No obstante, ya que nuestra intención en esta investigación es ilustrar de manera sucinta cómo se pueden aprovechar las fuentes por parte de la historiografía centrada en la historia de la frontera gráfica, hemos escogido, pues, tres de esos temas que conforman los estudios de la disciplina: determinadas fórmulas de los documentos y sus elementos de validación y ciertos aspectos referentes a los notarios.

Continuando con el esquema esbozado anteriormente para las cuestiones paleográficas, tras la confrontación de las jerarquías documentales de las diócesis se observa que las confirmaciones de las iglesias emitidas en Braga y los títulos colativos de beneficios en Tui poseen un formulario similar, aunque con algunas alteraciones de gran trascendencia. Expedidas en latín y pergamino hasta mediados del siglo XV, una de esas diferencias fue el inicio del texto, el cual, en la cancillería portuguesa, se correspondía con la intitulación del arzobispo, mientras que en la tudense con la notificación Noverint universis quod. Otra desigualdad se constata a simple vista en los mecanismos de validación, pues en Braga normalmente llevaban como únicos elementos el sello de cera pendiente del prelado y su firma (y esta no siempre hasta la llegada a la mitra de Lorenzo Vicente), mientras en Tui añadían a estos dos componentes o la firma de un notario o bien la suscripción y signo notarial; pudiendo utilizar todos estos mecanismos conjuntamente en un único documento a partir de finales del siglo XIV. Una validación, esta última, más semejante a la utilizada en la cancillería compostelana en el Cuatrocientos, pero donde los títulos de colación de beneficios, al igual que en Braga, comenzaban con la intitulación ${ }^{63}$. Si la realidad tudense parece situarse a medio

63 Una coincidencia, por otra parte, nada aleatoria, sino que habría que ponerla en relación con el mimetismo de los productos escritos de estas oficinas con la pontificia. En el caso compostelano: Adrián ARES LEGASPI, La escritura ... [ver n. 52], p. 392. Para la casuística portuguesa: Maria Cristina AlmEIDA e CUNHA, Traces de la documentation pontificale dans les documents épiscopaux de Braga (1071-1224), en Peter HERDE y Hermann JAKOBS (eds.), Papsturkunde und europäisches Urkundenwesen. Studien zu ibrer formalen und rechtlichen Kobärenz vom 11. bis 15. Fabrbundert, Köln, 1999, pp. 259-270; José MARQUES, A influencia das bulas papais na documentaçao medieval portuguesa, en Revista da Faculdade de Letras. Historia, 13 (1996), pp. 25-62. 
camino entre ambos arzobispados, la praxis desarrollada a partir de la década de 1380 en el área de Entre Minho e Lima continuará esa senda ecléctica, puesto que el diploma se inicia por la notificación y la validación se realiza únicamente con la firma del administrador y la aposición de su sello pendiente y, a partir de 1414 , la firma del notario a la derecha ${ }^{64}$ (en ningún momento, por lo tanto, aparecerá la completio notarial entera $)^{65}$. ¿Podría significar esto que las autoridades de Tui y Valença, en tanto que obispos -y por lo tanto en un escalón inferior a los arzobispos-, debían empezar sus confirmaciones por la notificación, mientras que el formulario iniciado por la intitulación estaba reservado a las dignidades superiores -la bracarense y la compostelana-, considerándose más próximas a la figura del pontífice? Y al mismo tiempo, ¿que los administradores del obispado de Tui en Portugal, tras un período de incertidumbre inicial, mantuvieron la práctica tudense, aunque sin llegar a optar por las validaciones más completas? No es este el lugar para dar cumplida respuesta a estos interrogantes, pero su planteamiento demuestra que la historia de las fronteras gráficas se compone de infinidad de aristas difícilmente resolubles en una aproximación preliminar como esta.

Por su parte, en la documentación menos solemne, donde, como vimos, las diferencias eran causadas por la aproximación de la escrituración del gallego en Tui a la tradición gráfica castellana, también se constata toda una serie de continuidades y discontinuidades en los formularios a ambas orillas del Miño. Es más, debido a las similitudes de las características de algunos de ellos, como las correspondientes a las cartas de aforamiento, podríamos considerarlos más cercanos entre sí, estableciendo, pues, una frontera entre la práctica notarial de Braga y Tui (tanto en suelo español como portugués) respecto, por ejemplo, a lo acontecido en Santiago de Compostela ${ }^{66}$. Mientras en la Baja Edad Media en los primeros se utilizaba la expedición de originales múltiples, consignándolo así en una de las últimas cláusulas del documento (mandarom a min, escriupuam

64 Los ejemplares de confirmaciones de los primeros años de andadura de esta corporación no contienen la firma de ningún notario acompañando a la del administrador. Será a partir de 1414, en la última de las confirmaciones otorgadas durante el gobierno de Antonio de Lisboa, y justo antes del período de sede vacante, cuando, a excepción de contadas ocasiones, este elemento de validación aparezca de manera constante.

65 Para una extensa muestra del formulario de las confirmaciones: José MARQUES, Confirmações... [ver n. 48].

66 Aunque la comparación entre los documentos notariales de estas provincias escriturarias puede ser extendida a todas las tipologías, aquí solamente nos centramos en las cartas de aforamiento por motivos de espacio y, al mismo tiempo, por el abundante número que conservamos de estos diplomas y la variedad de fórmulas que los componen. 
ajuso, scripto fazer dous prazos, anbos de buun theor en los documentos portugueses o pediron senllos instromentos anbos feitos sub vn thenor en los tudenses), en la capital del arzobispado gallego la mención a la existencia de dos originales múltiples parece haber desaparecido de los formularios en los siglos XIV y XV, ya fuera en los foros otorgados por la iglesia compostelana o bien por parte de particulares ${ }^{67}$. Esta coincidencia en ciertos aspectos formales de estos diplomas parece ocurrir también en otros elementos, aunque de manera menos constante. Si en los arrendamientos realizados en Braga (tipología denominada prazo), la mención de la presencia del notario en la actio va al inicio del documento, normalmente, tras la alusión a los otorgantes, expresando, asimismo, el tipo de nombramiento que poseía este profesional de la pluma y figurando en la suscripción únicamente la referencia notario sobredicho, en Tui esta tendencia es igualmente palpable, aunque se reproduce con una frecuencia menor; y nada que ver con la praxis compostelana, donde la identificación del notario va en la suscripción. Del mismo modo, y en relación con estas prácticas documentales, si los signos de los notarios públicos laicos bracarenses suelen ubicarse bajo su suscripción y en una posición centrada, en Tui esta localización alternará habitualmente con los signos colocados dentro de la suscripción, ya sea centrados o desplazados hacia la derecha ${ }^{68}$.

No obstante, la tentación de dibujar esa nítida línea que marque o defina la praxis documental de un territorio pronto se desvanece, ya que comprobamos que, incluso dentro de las cartas de arrendamiento, el formulario de las expedidas en Tui comparte otros componentes con los usos diplomáticos de Santiago y no con los bracarenses. Hablamos, en este caso, de la fórmula que inicia el documento, la cual, en Braga, dejando a un lado los prazos otorgados por el arzobispo (comenzados siempre por la intitulación), suele ser la notificación; mientras que en los del obispado tudense la datación semeja ser más recurrente, aunque en ocasiones esta es precedida por la notificación. Ahora bien, lejos de poder parecer una variación regional, si llevamos la vista a Santiago, observamos que la preferencia por la datación para el inicio de estos diplomas en el ámbito del derecho privado está más asentada, por lo que en este caso cabría preguntarse si esta tendencia, que se opone al esquema general planteado para los documentos redactados en

67 Si bien, este tema merece una atención más detenida, puesto que en la villa de Noia, perteneciente a dicho arzobispado, todavía se utiliza este mecanismo de expedición documental en el siglo XV.

68 Esta era la forma más común en la praxis del notariado en Castilla durante la Baja Edad Media: Pilar Ostos SALCEDO, Los escribanos públicos y la validación documental, en La validación de los documentos: pasado, presente y futuro, Huelva, 2007, p. 34. 
forma subjetiva en la tradición castellana ${ }^{69}$, se trata de una divergencia particular del territorio gallego y, de ser así, cuáles serían sus causas ${ }^{70}$.

Antes de finalizar este análisis de las cuestiones referentes al notariado, apreciamos todavía otra distinción que nos lleva a situar una frontera entre los diplomas otorgados a ambos lados del río Miño y los que venimos viendo para la casuística de Santiago. Se trata de la presencia del notariado apostólico en las tareas de escrituración, la cual -a falta de estudios comparados para el noroeste peninsular- parece mucho mayor en el arzobispado compostelano que en las diócesis de Tui y Braga $^{71}$. Se trata esta de una realidad que se evidencia claramente en las confirmaciones y títulos colativos de las sedes meridionales. Como ya hemos señalado más arriba, a lo largo de los siglos XIV y XV en la bracarense solamente aparece la firma del otorgante (el prelado o un delegado suyo); mientras que en la tudense (sea en territorio gallego o portugués) la del obispo se acompañaba de la firma de un escribano y en otras ocasiones de la suscripción de un notario apostólico. Por su parte, en Santiago, sobre todo en el siglo XV, la tónica general en los títulos de beneficios eclesiásticos es la de la validación documental no solo a través de la firma y sello del arzobispo, sino también del signo y suscripción de un oficial de nominación apostólica ${ }^{72}$. Esto no quiere decir, bajo ningún concepto, que la presencia de los notarios apostólicos no fuese frecuente en el Reino de Portugal ${ }^{73}$, sino que estaría más extendida en el arzobispado compostelano, y estas figuras serían -a la luz de las fuentes- más participativas en las tareas cotidianas de escrituración, principalmente, de las instituciones eclesiásticas ${ }^{74}$. De hecho, mientras que en la sede bracarense los encontramos con cierta recurrencia ejerciendo al servicio del cabildo catedralicio a lo largo del Cuatrocientos ${ }^{75}$, en

69 Según Ostos Salcedo: «los documentos redactados en forma subjetiva suelen comenzar por una notificación general» y «la data aparece siempre al final». Pilar OSTOS SALCEDO, El documento notarial castellano en la Edad Media, en Paolo CHERUBINI y Giovanna NiCOLAJ (eds.), Sit liber gratus, quem sevulus est operatus, Città del Vaticano, 2012, t. I, pp. 529 y 532.

70 En Braga, sin embargo, la datación en los prazos se sitúa al final del documento, tras la mención a la confección de dos originales.

71 Adrián AREs LEgASPI, Los notarios apostólicos en Santiago de Compostela a través de sus nombramientos, en Scrineum, 17 (2020), pp. 331-402.

72 Adrián ARES LEGASPI, La escritura... [ver n. 52], p. 391.

73 Néstor Vigil MonTes, La institución notarial y sus documentos en el Reino de Portugal en la Edad Media, en Historia. Instituciones. Documentos, 44 (2017), p. 358.

74 ARES LEgasPI, Adrián, Tipos de notarios y especialización gráfica en Santiago de Compostela en el siglo XV, en SVMMA. Revista de cultures medievals, 12 (2018), pp. 48-51.

75 Petrus Laurentii, canonicus Bracharense, publicus apostolica er regia auctoritatibus notarius (BRAGA, ADB, CC, 995, diploma de 1416) o Gonçallo Gonçaluez, clérigo do arçebispado de Braga e notario público per autoridade apostólica (BRAGA, ADB, CC, 1145 y 1170, documentos de 1435 y 1439, respectivamente). 
la tudense parece que su actuación se incrementó hacia las últimas décadas de la centuria, ya fuese interviniendo en los títulos colativos de beneficios eclesiásticos y algún otro documento o como sustitutos de los notarios del cabildo de la catedral ${ }^{76}$. Hasta entonces, sin embargo, algunos de los notarios apostólicos que hallamos en la documentación expedida en Tui por los obispos procedían de otras diócesis como la de Limoges o la vecina Ourense; mientras que algunos de los escribanos intitulados público jurado da çidade e bispado de Tui tienden a realizar una completio notarial muy peculiar: o bien sitúan su signo laico a la izquierda de la suscripción o añaden a su diseño -pudiendo estar el signo a la izquierda de la suscripción o bajo ella- alguno de los elementos de los utilizados por los apostólicos: una peana, unos trazos oblicuos que se cruzan en aspa en la parte alta..., pero nunca las llaves en sotuer, la cruz o su nombre en el propio dibujo ${ }^{77}$. ¿Se debería la ausencia de estos profesionales a su carácter itinerante, el mismo que tenían algunos de estos notarios en otros territorios no muy lejanos como el de Oporto? ${ }^{78}$ ¿Se explicaría la adopción de esos elementos en sus signos o su posicionamiento a la izquierda de la suscripción como una cuestión de formación del notario o como un aspecto cultural? Preguntas que, desafortunadamente, han de esperar a una investigación específica.

Una última faceta que cabe destacar dentro de la frontera gráfica es la de la lengua ${ }^{79}$. Un elemento al que los paleógrafos y diplomatistas no siempre dedican la atención necesaria, pero que, en un espacio de frontera como este, es de

76 Alfonso Salinas, canónigo en la iglesia de Tui, notario público jurado por las autoridades apostólicas (...) e escusador del bachiller Fernán Pérez, notario del cabildo (TUI, ACT, C. 10, doc. 11, año de 1504) o Francisco Estéuez de Bugarín, clérigo de la dicha cibdad de Tuy por la abtoridad apostólica público notario scriuano e notario del dicho cabildo en lugar del vachiller Alonso de Bugarín (TUI, ACT, C. 12, doc. 27, año de 1520).

77 Para el estudio de los componentes de los signos de los notarios apostólicos: Francisco Reyes Marsilla de Pascual, Notariado eclesiástico de la Iglesia de Cartagena (s. XV): 1.- Los signos notariales, en Anales de la Universidad de Alicante: Historia medieval, 10 (1994-1995), pp. 237-253. Para el caso de Braga solamente hemos encontrado un ejemplo de esta realidad, el de Vaasco Martim, tabelliom da dita cidade (Braga) per autoridade do dito senhor arçobispo, cuyo signo se compone de un cuadrado central rodeado de varios arcos y ubicado sobre una peana (BRAGA, ADB, CC, 869, diploma de 1376) y que en otras ocasiones podía ser trazado de una manera más simple (BRAGA, ADB, CC, 894, diploma de 1387).

78 Dora Sara Lima Couto Ramos Farinha, Notários apostólicos na documentação do Cabido e Sé do Porto (1425-1543), Dissertação de Mestrado inédita, Universidade do Porto, 2015, p. 112.

79 Para la aplicación del concepto de frontera al ámbito de la sociolingüística: Michel CONTINI, Présent et passé: la notion de frontière dans une lecture interdisciplinaire de l'espace linguistique, en Rosario Álvarez, Francisco Dubert García, Xulio SOUSA FERNándEZ (eds.), Lingua e territorio, Santiago de Compostela, 2006, pp. 23-54. 
especial relevancia a la hora de determinar las similitudes y diferencias entre las provincias escriturarias y los efectos que el uso de un idioma u otro tuvo sobre los aspectos gráficos y diplomáticos. La comparación entre los documentos en romance de los fondos de los archivos de Braga y Tui revela la coexistencia de dos lenguas consolidadas, el portugués y el gallego ${ }^{80}$. Cuanto más nos acercamos al tránsito de la Edad Media a la Moderna el primero se va a configurar en un «portugués novo, ben diferenciado das xa vellas formas galaico-portuguesas do Norte, e moi próximo das características modernas da lingua ${ }^{81}$, al mismo tiempo que el segundo será sustituido por el castellano en los usos escritos que le eran propios en las centurias pasadas ${ }^{82}$. No obstante, si el empleo de un idioma concreto tuvo un efecto evidente sobre la cultura gráfica este fue el caso del latín, puesto que, como hemos tratado anteriormente, este implicaba la utilización de la mixta francesa ${ }^{83} \mathrm{y}$, por lo tanto, su abandono determinaría también la caída -o al menos una marcada reducción- en el uso de dicho modelo gráfico. Este proceso parece haberse producido en las confirmaciones otorgadas por el arzobispo de Braga en los años centrales del siglo XV, durante el pontificado de Fernando da Guerra; momento en el que dejamos de ver en estos diplomas las formas más características de la superestructura gráfica de la mixta, para encontrar una gótica de trazos más redondeados y con algún bucle dextrógiro, aunque con muchos de los elementos del modelo francés ya estandarizados en la

80 Una coexistencia que en diversas ocasiones se convirtió en una combinación en un mismo profesional de la pluma de elementos gráficos y lingüísticos de ambas lenguas, como se observa en el caso de Afom Estéuez, notario público jurado por noso senhor el rey en Tebra e Sobrada e dos mosteiros de Tominho e Barrantes e Oya e em seus coutos e em todo o bispado de Tuuy (TUI, ACT, C. 14, doc. 72). Se trata de un foro otorgado por el monasterio de San Salvador de Barrantes (en territorio gallego) y escriturado autógrafamente por un notario que utiliza la forma $n h$ (propia del portugués) para el grafema $\tilde{n}$; lo cual ratifica la teoría de continuidad y no ruptura entre lenguas/dialectos contiguos apuntada por Michel Contini: «dans la plupart des cas -sans nier le fait que des zones de ruptura existent sans doute- on observe plutôt des gradients montrant des transitions d'un espace à un autre espace». Michel ConTinI, Présent... [ver n. 79], p. 45.

81 Juan M. CARrasco González, A lingua portuguesa na fin da Idade Media, en Ramón MariÑo PaZ y Xavier VAREla BARREIRo (eds.), A lingua galega no solpor medieval, Santiago de Compostela, 2016, p. 39.

82 Henrique Monteagudo Romero, Historia social da lingua galega: idioma, sociedade e cultura a través do tempo, Vigo, 2017.

83 El vínculo entre esta lengua y el modelo gráfico de origen francés ya ha sido subrayado por Carmen del CAMINO MARTÍNEZ, El notariado apostólico en la Corona de Castilla: entre el regionalismo y la internacionalización gráfica, en Otto KRESTEN y Franz LACKNER (eds.), Régionalisme et internationalisme: problèmes de paléographie et de codicologie du Moyen Âge, Wien, 2008, pp. 317330. 
tradición gráfica lusa ${ }^{84}$. Mientras tanto, en los títulos de beneficios eclesiásticos expedidos por el obispo tudense se mantiene la utilización del latín a lo largo del Cuatrocientos -a excepción de alguno en castellano-, lo cual nos permite rastrear la introducción de la escritura humanística en esta tipología documental desde -como mínimo- los años $80^{85}$.

\section{CONSIDERACIONES FINALES}

La investigación aquí desarrollada refleja cómo el análisis comparado (sincrónico y diacrónico) de los fondos documentales de varias diócesis limítrofes permite abordar la historia de la frontera gráfica en la Edad Media, entendiéndola como el espacio físico y de expedición documental donde convergen (influenciándose y contraponiéndose entre ellas) varias culturas y prácticas escriturarias, cada una compuesta de una compleja jerarquía de tipologías de productos escritos, unos modelos gráficos determinados y unos usos y funciones de la escritura bien definidos. Aspectos que, en la divisoria entre la diócesis portuguesa y la gallega, lejos de corresponderse con provincias escriturarias enfrentadas, independientes una de otra, actúan como punto de unión entre ellas. De esta forma, la utilización de la mixta francesa en los documentos más solemnes o el recurso a otros mecanismos como la emisión de originales múltiples en ciertas ocasiones, o incluso cuestiones lingüísticas, muestran que el contacto, la transferencia, tanto de personas como de tendencias culturales entre los distintos territorios tiene una traducción efectiva sobre las culturas gráfica y documental de una amplísima zona.

En este sentido, la frontera gráfica difícilmente se ajusta a la política-jurisdiccional o a la institucional, ya que, dependiendo del elemento paleográfico y

84 En Valença do Minho, sin embargo, se aprecia una tendencia más o menos continuada en el tiempo a emitir las confirmaciones en portugués desde la década de 1430 en adelante, coincidiendo, además, con el desplazamiento de la intitulación del administrador João Afonso al inicio del diploma: BRAGA, ADB, CC, 1084 y 1106. Esta variación nos demuestra que, dentro de la perspectiva diacrónica, los aspectos individuales relativos a cada uno de los dirigentes de las cancillerías episcopales pueden explicar la evolución de muchos de los elementos de la documentación. Es por ello que, ya que esta es una aproximación inicial, una investigación pormenorizada de cada arzobispo, así como del personal de sus oficinas -su formación y experiencia previa, entre otras-, nos aportaría una información complementaria e imprescindible.

85 Una cronología bastante similar a la ya vista en la diócesis compostelana: Adrián ARES LEGASPI, La introducción de la escritura bumanística en la Iglesia de Santiago de Compostela: fechas, protagonistas y características, en María Luisa PARDO RODRÍGUEZ (ed.), Iglesia y Escritura en Castilla. Siglos XIIXVII, Sevilla 2019, pp. 13-43. 
diplomático analizado, las diferencias entre los diplomas de Braga y Tui pueden disminuir o aumentar, la frontera puede estrecharse o ensancharse, sobre todo esto último en el siglo XV, cuando parece que la cultura gráfica de Tui se aproxima mucho más a la de Santiago de Compostela y, consecuentemente, a la de la Corona de Castilla.

Ahora bien, tampoco la realidad vivida en la diócesis tudense debe ser considerada como un continuum homogéneo, ya que dentro de sus límites el obispo y el cabildo debieron convivir con otras autoridades que también hacían un uso frecuente de la escritura, generando, así, dinámicas gráficas y diplomáticas específicas e igualmente delimitables. De esta forma, los monasterios, las familias nobiliarias de los Sarmiento y los Soutomaior, señores de Sobroso, o villas reales como la de Baiona hacen que la frontera gráfica se sitúe no solo en los límites exteriores de la diócesis, sino también en su interior. Los mecanismos de expedición documental en cada una de estas jurisdicciones, sus autores materiales o las características de sus escrituras suponen unas fronteras gráficas interiores en Tui que, por ahora, restan a la espera de ser estudiadas, matizadas o incluso diluidas por parte de la historiografía.

\section{REFERENCIAS BIBLIOGRÁFICAS}

\section{Archivos}

Braga, Arquivo Distrital de Braga, Colección Cronológica, 869, 893, 894, 899, 918, 919, 930, 933, 968, 977, 987, 992, 995, 1010, 1036, 1045, 1084, 1095, 1106, $1145,1170,1186,1200,1203,1210,1247,1253,1354,1355,1357,1361,1382$, 1495.

Santiago de Compostela, ArChivo de la Catedral de Santiago de ComposTELA, Documentos sueltos:

Carpeta 13.

Carpeta 14.

TUI, ARCHIVO CATEDRALicio DE TUI:

Carpeta 9, documento 18, 20.

Carpeta 10, documento 11, 20.

Carpeta 11, documento 5, 6, 7, 13 .

Carpeta 12, documento 6, 14, 15, 26, 27, 29.

Carpeta 13, documento 15, 23, 35.

Carpeta 14, documento 28, 29, 45, 58, 72, 82. 


\section{Bibliografía}

AREs LEGASPI, Adrián, Tipos de notarios y especialización gráfica en Santiago de Compostela en el siglo XV, en SVMMA. Revista de cultures medievals, 12 (2018), pp. 42-56.

ARES LEGASPI, Adrián, La escritura en Santiago de Compostela en el tránsito de la Edad Media a la Edad Moderna, Tesis doctoral inédita, Universidad de Sevilla, 2019.

ARES LEGASPI, Adrián, La introducción de la escritura bumanistica en la Iglesia de Santiago de Compostela: fechas, protagonistas y características, en PARDO RODRÍGUEZ, María Luisa (ed.), Iglesia y Escritura en Castilla. Siglos XII-XVII, Sevilla, 2019, pp. 13-43.

ARES LEGASPI, Adrián, Los notarios apostólicos en Santiago de Compostela a través de sus nombramientos, en Scrineum, 17 (2020), pp. 331-402.

Ávila y La CuEva, Francisco, Historia civil y eclesiástica de la ciudad de Tuy y su obispado, edición facsímil, Santiago de Compostela, 1995.

Barros Guimerans, Carlos, La frontera medieval entre Galicia y Portugal, en Medievalismo, 4 (1994), pp. 27-39.

Bradbury, Carlee A. y Moseley-Christian, Michelle (eds.), Gender, Otherness, and Culture in Medieval and Early Modern Art, London, 2017.

Cabanes Catalá, María Luisa y BALDAquí EsCANDEll, Ramón, La regionalización de la escritura en zonas de frontera gráfica. El caso de la gobernación de Alicante, en KRESTEN, Otto y LACKNER, Franz (eds.), Régionalisme et internationalisme: problèmes de paléographie et de codicologie du Moyen Âge, Wien, 2008, pp. 177-188.

CALDERón MEDINA, Inés, Reyes, nobles y frontera. Entre la violencia y el parentesco en el espacio fronterizo galaico portugués (siglos XII-XIII), en Cuadernos de Estudios Gallegos, 64 (2017), pp. 91-117.

Calleja Puerta, Miguel, Notarios públicos entre dos reinos. Apuntes diplomáticos sobre documentos notariales castellanos en el Arquivo Distrital de Braga, en Espacio, Tiempo y Forma. Serie III, Historia Medieval, 33 (2020), pp. 69-96.

CAMino MartíneZ, Carmen del, El notariado apostólico en la Corona de Castilla: entre el regionalismo y la internacionalización gráfica, en KRESTEN, Otto y LACKNER, Franz (eds.), Régionalisme et internationalisme: problèmes de paléographie et de codicologie du Moyen Age, Wien, 2008, pp. 317-330.

CÁRCEL OrTí, María Milagros, El documento episcopal: estado actual de sus estudios, en Boletín de la Sociedad Castellonense de Cultura, 58, 3 (1982), pp. 471-511.

Carrasco González, Juan M., A lingua portuguesa na fin da Idade Media, en MARIÑO PAZ, Ramón y VAREla BARreiro, Xavier (eds.), A lingua galega no solpor medieval, Santiago de Compostela, 2016, pp. 39-66.

CECCHERINI, Irene, Structure et style: observations paléographiques pour l'étude des écritures cursives à Florence aux XIII et XIV siècles, en BARRET, Sébastien; STUTZMANN, Dominique y VOGELER, Georg (eds.), Ruling the script in the Middle Ages, Turnhout, 2016, pp. 109-130.

CONTINI, Michel, Présent et passé: la notion de frontière dans une lecture interdisciplinaire de l'espace linguistique, en Álvarez, Rosario; DuberT GARCÍA, Francisco y SOU- 
SA FERnándeZ, Xulio (eds.), Lingua e territorio, Santiago de Compostela, 2006, pp. 23-54.

Costa, Avelino Jesús da, A comarca eclesiástica de Valença do Minho (Antecedentes da diocese de Viana do Castelo), en I Coloquio galaico-minhoto, Ponte de Lima, 1981, pp. 69240.

Cunha, Maria Cristina Almeida e, Traces de la documentation pontificale dans les documents épiscopaux de Braga (1071-1224), en HERDE, Peter y JAKOBS, Hermann (eds.), Papsturkunde und europäisches Urkundenwesen. Studien zu ibrer formalen und rechtlichen Kobärenz vom 11. bis 15. Jabrbundert, Köln, 1999, pp. 259-270.

CunHa, Maria Cristina Almeida e, A chancelaria arquiepiscopal de Braga (1071-1244), Noia, 2004.

FARINHA, Dora Sara Lima Couto Ramos, Notários apostólicos na documentação do Cabido e Sé do Porto (1425-1543), Dissertação de Mestrado inédita, Universidade do Porto, 2015.

Ferreira, João Paulo Martins, A Nobreza Galego-Portuguesa da Diocese de Tui (915-1381), Santiago de Compostela, 2019.

FICHTENAU, Heinrich von, Das Urkundenwesen in Österreich vom 8. bis zum frühen 13. Fabrbundert, Wien, 1971.

FONSECA, Luís Adão da (coord.), Entre Portugal e a Galiza (sécs. XI a XVII). Um olhar peninsular sobre uma região bistórica, Porto, 2014.

Galindo RomeO, Pascual, Tuy en la Baja Edad Media: siglos XII-XV, Zaragoza, Madrid, 1923.

GARCÍA FERnÁNDEZ, Manuel; GALÁN SÁNCHEZ, Ángel y PEINADO SANTAELLA, Rafael Gerardo (eds.), Las fronteras en la Edad Media hispánica, siglos XIII-XVI, Granada, 2019.

GARCÍA ORO, José, Galicia en los siglos XIV y XV, A Coruña, 1987.

GARCÍA SERRANO, Francisco, La creación de identidad en la frontera medieval hispana y la visión del otro: mudéjares y judíos, en RODRÍGUEZ DE LA PEÑA, Manuel Alejandro (dir.), Hacedores de Frontera. Estudios sobre el contexto social de la Frontera en la España medieval, Madrid, 2009, pp. 73-90.

GONZÁLEZ JimÉNEZ, Manuel, Fuentes para la bistoria de la frontera castellano-granadina, en Rodríguez de la PEÑa, Manuel Alejandro (dir.), Hacedores de Frontera. Estudios sobre el contexto social de la Frontera en la España medieval, Madrid, 2009, pp. 1526.

Iglesias Almeida, Ernesto, O antigo bispado de Tui en Portugal, Noia, 2008.

LADERO QUESADA, Miguel Ángel, Reconquista y definiciones de frontera, en Revista da Faculdade de Letras. História, 15 (1998), pp. 655-691.

MANSILla REOYO, Demetrio, Geografía eclesiástica de España: estudio bistórico-geográfico de las diócesis, Roma, 1994, vol. 2.

MARQUES, José, Relações galaico-bracarenses, no século XV, segundo as matrículas de ordens do Arquivo Distrital de Braga, en I Coloquio galaico-minhoto, Ponte de Lima, 1981, pp. 339-359. 
MARQUes, José, O Mosteiro de Oia e a Granja da Silva, no contexto das relações luso-castelhanas dos séculos XIV-XV, en Revista de história, 6 (1985), pp. 97-120.

MARQUES, José, O regimento da Chancelaria Arquiepiscopal de Braga no século XV: tipologia documental e taxas, en Revista da Faculdade de Letras. História, 9 (1992), pp. 87-106.

MARQUES, José, A chancelaria e a diplomática arquiepiscopais de Braga nos finais da Idade Média, en Revista de História, 12 (1993), pp. 25-46.

MARQUES, José, A influencia das bulas papais na documentaçao medieval portuguesa, en Revista da Faculdade de Letras. Historia, 13 (1996), pp. 25-62.

MarQues, José, Prácticas paleográficas em Portugal no século XV, en Revista da Faculdade de Letras do Porto, Ciências y Técnicas do património, Série I, 1 (2002), pp. 73 96.

MARQUES, José, A fronteira do Minho, espaço de convivência galaicho-minhota, na Idade Média, en Estudos em Homenagem a Luís António de Oliveira Ramos, Porto, 2004, pp. 697-712.

MARQues, José, O Entre Minho e Lima: da diocese de Tui à diocese de Ceuta, en GONZÁLEZ Jiménez, Manuel y Montes Romero-CAmaCHO, Isabel (eds.), La Península Ibérica entre el Mediterráneo y el Atlántico. Siglos XIII-XV, Sevilla, Cádiz, 2006, pp. 481498.

MARQues, José, O Cartulário do Mosteiro de Fiães (ADB, MS. 1052), Melgaço, 2016.

MARQues, José, O Censual do Cabido de Tui para o arcediagado da Terra da Vinha 1321, en ID., Alto-Minho e Galiza. Estudos históricos, Monção, Braga, Melgaço, 2017, pp. 367393.

MARQUes, José, Relações económicas do norte de Portugal com o Reino de Castela, no século XV , en ID., Alto-Minho e Galiza. Estudos históricos, Monção, Braga, Melgaço, 2017, pp. 493-530.

MARQUES, José, Relações fronteiriças luso-castelhanas, nos séculos XIV-XV, en ID., Alto-Minho e Galiza. Estudos históricos, Monção, Braga, Melgaço, 2017, pp. 453-492.

MARQUES, José, Confirmações de Tui (1352-1382): aspectos do episcopado de D. Foão de Castro, Braga, 2018.

Marsilla de Pascual, Francisco Reyes, Notariado eclesiástico de la Iglesia de Cartagena (s. XV): 1.-Los signos notariales, en Anales de la Universidad de Alicante: Historia medieval, 10 (1994-1995), pp. 233-260.

MARSILla DE PASCUAL, Francisco Reyes, En torno a la diplomática episcopal y capitular castellana bajomedieval: una aproximación, en Miscelánea medieval murciana, 19-20 (1995-1996), pp. 153-172.

Mitre FernándeZ, Emilio, El Occidente Medieval y el «otro», en XX Siglos, 5, 19 (1994), pp. 14-22.

Monteagudo Romero, Henrique, Historia social da lingua galega: idioma, sociedade e cultura a través do tempo, Vigo, 2017.

Nunes, Eduardo, Album de Paleografia Portuguesa, Lisboa, 1969.

Ostos SALCEDO, Pilar, Los escribanos públicos y la validación documental, en La validación de los documentos: pasado, presente y futuro, Huelva, 2007, pp. 27-42. 
Ostos SALCEDO, Pilar, El documento notarial castellano en la Edad Media, en CHERUBINI, Paolo y NICOLAJ, Giovanna (eds.), Sit liber gratus, quem servulus est operatus, Città del Vaticano, 2012, t. I, pp. 517-534.

PETERS, Edwar, Omnia permixta sunt: Where's the Border?, en The Medieval History Fournal, 4, 1 (2001), pp. 109-127.

PORTEla Silva, Ermelindo, La región del obispado de Tuy en los siglos xii a xv: una sociedad en la expansión y en la crisis, en Compostellanum, 20, 1-4 (1975), pp. 1-468.

PORTELA SILVA, Ermelindo, Tiempos de reforma y espacios de frontera. En torno a los orígenes del monasterio de Santa María de Oia, en Revista Chilena de Estudios Medievales, 12 (2017), pp. 49-60.

PowEr, Daniel, Frontiers: Terms, Concepts, and the Historians of Medieval and Early Modern Europe, en POWER, Daniel y STANDEn, Naomi (eds.), Frontiers in question. Eurosian borderlands, 700-1700, Basingstoke, 1999, pp. 1-12.

RODRIGUES, Ana Paula Leite, En torno a un territorio periférico y fronterizo: la relación del Monasterio de Santa María de Oia con el poder regio portugués (siglos XII a XV), en Studia Historica. Historia Medieval, 34 (2016), pp. 215-242.

Rodrigues, Ana Paula Leite, Nos dois lados do rio Minho: o senhorio transfronteiriço do mosteiro de Santa Maria de Oia (séculos XII a XV), Vigo, 2017.

RoDrigues, Teresa de Jesus, O Entre Minho e Lima de 1381 a 1514: antecedentes e evolução da comarca eclesiástica de Valença do Minho, Viana do Castelo, 2002.

Rodríguez PiCAVEA, Enrique, The Frontier and Royal Power in Medieval Spain: A Developmental Hypothesis, en The Medieval History fournal, 8, 2 (2005), pp. 273-301.

Romero PorTilla, Paz, Valor de la documentación real portuguesa para la historia de Galicia en la Edad Media, en Cuadernos de Estudios Gallegos, 51 (2004), pp. 219-237.

Romero Portilla, Paz, Un Observatorio privilegiado de las relaciones entre Castilla y Portugal: Tuy en la Edad Media, en Estudos em homenagem ao professor doutor Fosé Marques, vol. 4, Porto, 2006, pp. 247-259.

Romero Portilla, Paz, Relaciones entre Portugal y Galicia. Siglo XIV-XV, en Revista da Faculdade de Letras. História, 9 (2008), pp. 217-269.

SÁnCheZ CARrera, María del Carmen, El Bajo Miño en el siglo XV: el espacio y los hombres, A Coruña, 1997.

SANZ Fuentes, María Josefa, La escritura gótica documental en la Corona de Castilla, en SAnZ Fuentes, María Josefa y Calleja Puerta, Miguel (coords.), Paleografía II: las escrituras góticas desde 1250 basta la imprenta, Oviedo, 2010, pp. 107-126.

SILVA, Maria João Oliveira e, A escrita na catedral. A chancelaria episcopal do Porto na Idade Média, Porto, 2013.

SMITH, Marc, L'écriture de la chancellerie de France au XIV siècle: observations sur ses origines et sa diffusion en Europe, en KRESTEN, Otto y LACKNER, Franz (eds.), Régionalisme et internationalisme: problèmes de paléographie et de codicologie du Moyen Âge, Wien, 2008, pp. 279-298.

VÁzQuez CoRbal, Margarita, Entre Galicia y Portugal: la catedral de Tui y el rol de la frontera en la génesis y evolución del arte medieval en los siglos XIII y XIV, en GARCÍA 
Fernández, Manuel; Galán SÁnchez, Ángel y Peinado Santaella, Rafael Gerardo (eds.), Las fronteras en la Edad Media hispánica, siglos XIII-XVI, Granada, 2019, pp. 673-683.

VigIL MonTES, Néstor, De la unidad a la diversificación, los nuevos usos escriturarios en la gestión del patrimonio capitular de Oviedo, en MOLINA DE LA TORRE, Francisco J.; RUIZ AlbI, Irene y HERRERO DE LA FUENTE, Marta (eds.), Lugares de escritura: la catedral, Valladolid, 2014, pp. 463-480.

VigIL MonTes, Néstor, La institución notarial y sus documentos en el Reino de Portugal en la Edad Media, en Historia. Instituciones. Documentos, 44 (2017), pp. 351-379.

Vila Botanes, Suso, A cidade de Tui durante a Baixa Idade Media, Noia, 2009.

YZquierdo PERRín, Ramón, Talleres de Tui, Braga y Zamora en la arquitectura románica del norte de Portugal y Galicia, en Anuario Brigantino, 39 (2016), pp. 195-218. 